\title{
Pain, objectivity and history: understanding pain stigma
}

\author{
Daniel S Goldberg
}

\section{Correspondence to}

Dr Daniel S Goldberg, Faculty, Center for Bioethics and Humanities, Associate Professor (pending), Department of Family Medicine, Fulginiti PavilionRoom 205, 13080 E. 19th Avenue, CB B137, University of Colorado Anschutz Medical Campus, Aurora, CO 80045, USA;

daniel.goldberg@ucdenver.edu

Received 19 October 2016 Revised 11 January 2017 Accepted 24 January 2017 Published Online First 20 February 2017

\section{CrossMark}

To cite: Goldberg DS.

Med Humanit

2017:43:238-243.

\section{ABSTRACT}

The primary claim of this paper is that understanding the stigma so commonly endured by chronic pain sufferers today in the USA and the UK is unlikely without proper appreciation of the history of pain. Ameliorating such stigma is an ethical imperative, and yet most approaches eschew even an attempt to trace connections between historical attitudes, practices and beliefs towards pain and the stigmatisation so many pain sufferers currently endure. The manuscript aims to help fill this gap by framing pain in the modern era in context of two crucial intellectual schemes that waxed in the 19th and 20th centuries: mechanical objectivity and somaticism. The analysis explains these frameworks and applies them to exploration of primary sources connected to contested pain conditions such as railway spine. By properly situating the historical roots of what it means to cite the 'subjectivity' of pain as a problem, the modern roots of stigmatising attitudes and practices towards chronic pain sufferers become much clearer. The manuscript concludes by suggesting that interventions expressly intended to target the root causes of such stigma are much more likely to be successful than approaches that proceed in ignorance of the historical forces shaping and driving pain stigma in the present.

\section{INTRODUCTION}

Stigma is corrosive. It is capable of inducing intense psychosocial harm. It is a risk factor for suicide. ${ }^{1}$ Even when controlling for every conceivable confounder, members of groups subjected to persistent stigma get sicker and die quicker than comparators. $^{2}$ It is therefore important both as a social problem and as a health problem. Although health stigma takes many forms and attaches to many different illness conditions, this essay focuses on that which attends the most common illness experience on the planet: pain. While there are no good estimates of the prevalence of pain stigma, extensive qualitative evidence across a wide variety of settings documents that such stigma is an altogether typical experience. ${ }^{3-5}$ Certainly in the Anglophone world, where this paper focuses, there is no serious dispute that such stigma, and especially chronic pain stigma, is part and parcel of the illness experience for far too many.

Although the term 'stigma' is often used interchangeably with words like 'prejudice' and 'bias', understanding its specific meaning in health contexts is important to recognising it and intervening to reduce it. Stigma occurs where an in-group marks an out-group as different on the basis of a shared demographic characteristic, and attributes deviance to members of the out-group as a result of that characteristic. ${ }^{6}$ It is worth noting that stigma is a product of social power structures insofar as members of in-groups are by definition empowered by virtue of that group membership. This means that in any given social context, members of disadvantaged groups are more likely to experience stigma. Given the extent to which vulnerable groups (women, children, people of colour, etc) have historically endured pain stigma, understanding stigma as a product of social power is critical.

This essay takes for granted that reducing the stigma so many people in pain endure is an ethical imperative. The obvious question is 'how to do so?' Despite many successful multidisciplinary clinics, the dominant global and Western approach has been to focus on pharmaceutical policy. I have explained in prior work why this strategy is extremely unlikely to be successful. ${ }^{7}$ Here, I argue that to have any chance to alleviate the devastating burden of chronic pain stigma, we must take a historical approach. This makes sense where, for over a 1000 years, pain stigma has been an enduring feature of the experience in the West. ${ }^{8}$ This is not meant as a reduction; pain is obviously multivalent and dynamic. Nevertheless, among the vast multiplicity of lived experiences of pain in Western history, shame, fear and stigma have been relentless horsemen. ${ }^{9}$ It is not accidental, as Leder points out, that the Latin root of pain (poena) means punishment. ${ }^{10}$

This essay argues that the root causes of such pain-shaming are poorly understood, largely because stakeholders have not sufficiently turned to the history of pain without lesion ${ }^{\mathrm{i}}$ as a way of understanding the epistemological, social and political problems that such forms of pain pose for modern models of medical practice in particular. More specifically, one of the most significant modern paradigms for examining anxieties about pain without lesion ${ }^{11}$ is late 19 th to early 20 th century discourse on railway spine. ${ }^{\text {ii }}$ The essay surveys primary sources within this context, and suggests how, as the US pain physician Stratton Hill put it, attitudes about pain are systematically

${ }^{\mathrm{i}}$ Because disease categories were highly fluid in the 19th century, a variety of different terms can refer to what we would now tend to term chronic pain. This essay uses Andrew Hodgkiss' useful umbrella term of 'pain without lesion' to refer generally.

${ }^{i i}$ Although obviously the history of pain and stigma stretches back much farther than the modern era, I argue here that some distinctly modern forms of knowing have wreaked enormous mischief in intensifying stigma for the contemporary pain sufferer. This justifies modernity as the framework for analysis, although the focus herein is not meant to privilege it. 
transferred from one generation of healthcare providers to the next. ${ }^{12}$ If we wish to improve our practices and reduce the stigma that chronic pain sufferers ${ }^{\mathrm{iii}}$ endure, we must understand the root social causes driving these practices. History provides us with important clues as to these roots.

\section{PAIN, DOUBT AND SUBJECTIVITY}

Practitioners and pain studies scholars concur in noting that one of the principal reasons pain seems to incite so much doubt is that it is subjective. Yet virtually nowhere are the criteria for objectivity and subjectivity adequately theorised. What does it mean to say that pain is subjective? What makes other illness conditions objective? What critical features of the latter are absent from the domain of pain? And why should this matter?

Objectivity has a history. Even a cursory understanding of this history is essential not merely to framing objectivity/subjectivity, but to understanding what is at stake in the ascription of subjectivity to pain. Daston and Galison have produced the authoritative modern history of objectivity in the West, spanning over four centuries. ${ }^{13}$ It is important that the primary objects of their analysis are scientific images, represented through atlases, herbaria, compendia and medical texts. ${ }^{13}$ Objectivity in its various forms always centres on what the investigating scientific eye can discern in the production of scientific knowledge. Although Daston and Galison document at least four different concepts of objectivity, one of them is especially significant for understanding the connection between 19th century attitudes towards pain without lesion and contemporary approaches: mechanical objectivity. ${ }^{13}$ This concept begins its ascent in the early-to-mid-19th century, coterminous with significant changes in Western allopathic medicine. (As discussed below, the diachronic nature of these intellectual frameworks is not coincidental.) Under Daston and Galison's formulation, mechanical objectivity has two central features: first, the ideal representation features the elimination of human subjective influence over the knowledge-making process. Only where the subjectivity of human agency is excised can the mechanical processes of nature 'speak for themselves' and reveal truth. ${ }^{13}$ Second, the ideal representation is one that maintains fidelity to the specimen under investigation, no matter how imperfect it may be. ${ }^{13}$

Although few historians have expressly linked the wax of mechanical objectivity to the birth of the clinic, ${ }^{14}$ the connections are crucial for making sense of pain without lesion. Like mechanical objectivity, the birth of the clinic centres on sight, on what Foucault terms the clinical gaze. ${ }^{15}$ Laennec himself understood the stethoscope not as a listening device, but as an instrument for seeing inside the living body. ${ }^{16}$ Under this rubric, the twin suns of the clinical gaze are pathological anatomy and clinical correlation. The modern physician seeks to identify dysmorphologies that can be clinically correlated with the patient's illness complaint. These structures contain the truth of the patient's illness, subsumed in the (mechanical) pathophysiological changes. For physicians deeply invested in this epistemic framework, the patient's illness complaints themselves were inferior modes of knowing when compared with the truths of the body. Thus, in an 1881 treatise, American neurologist William Henry Hammond noted that

\footnotetext{
iii The use of the term 'sufferer' is consistent with established practice in health humanities scholarship, and is not meant to imply that any particular experience of illness or pain necessarily causes any particular
} person suffering.
The fact that the patient denies the existence of [spinal] tenderness should have no weight with the physician. Thus, a young lady consulted me for severe infra-mammary pain, headache, and nausea. I at once suspected spinal irritation, but she declared, in answer to my inquiries, that there was no sign of tenderness anywhere over the spinal column. I insisted, however, on a manual examination, and to her great surprise found three spots that were exceedingly painful to slight pressure. ${ }^{17}$

'At the dawn of the 19th century', notes historian of pain Roselyne Ray, 'physicians were looking for a pure sign which would remove the ambiguities inherent in symptoms. They wished to find a sign, the meaning of which would be as certain as that provided by the lesion found at dissection'. ${ }^{18}$ The problem posed by pain without lesion should be obvious. It defied the objectification of visual anatomical pathologies that forms the epistemic core of the clinical gaze. The typical response among 19th century physicians in both England and the USA denied the possibility that pain without lesion actually existed. ${ }^{19}$ There was only two kinds of pain: pain for which the structural lesions could be apprehended and pain for which the lesions had not yet been located (owing largely to technical limitations related to imaging the living body). ${ }^{17}$

Given its emphasis on material pathologies inside the body, we may refer to this epistemic framework as 'somaticism'. And, as Charles Rosenberg puts it, by the end of the 19th century, the social legitimacy of disease increasingly depended on 'somatic identity'. ${ }^{20}$ At the same time, the massive social changes that occurred in the 19th century West prompted significant anxiety that the world was no longer as it seemed and that it could not be trusted. ${ }^{21-24}$ Forensic science began to take on special social importance, and it is no surprise that detective fiction as a genre explodes in popularity at exactly this time, with the detective positioned as the forensic investigator (recall that Sir Arthur Conan Doyle was a physician).

In Western contexts of increased anxiety about deception and corresponding efforts to discern the truth of the matter via forensic investigation of the natural world, pain without lesion was increasingly problematic. Pathological objects that could be correlated with pain complaints were by definition difficult if not impossible to find. By the first quarter of the 20th c., such pain complaints were increasingly sites of doubt and contest between illness sufferers and physicians. One of the most active loci for such tension was railway spine.

\section{PAIN, DOUBT, AND RAILWAY SPINE}

Few late 19th century illness experiences proved as controversial as railway spine. Nosology remained fluid in this period, so the term refers to a conglomerate of symptoms that people reported experiencing in the aftermath of a railway accident. Pain was almost always a central feature of 'railway spine'. Multiple expert treatises and reports were written between the 1860s and 1890 s, and the issue provoked significant dispute and commentary in both lay and expert media. ${ }^{25-30}$

Given the intensity of the social anxieties regarding deception by the end of the 19th century, it is unsurprising that doubt, scepticism and concerns over feigned illness or 'malingering' were central. American railway surgeon Webb Kelly went so far as to claim that '[railway] surgery without the spinal malingerer would be like a ship in mid-ocean bereft of her sails and rudder'. ${ }^{31}$ Consider, for example, The Kildwick Railway Accident, which occurred on 28 August 1875. The passenger train was bound for Bradford on the return leg of a popular holiday trip jointly sponsored by the Midland Railway Company and the Bradford Saturday Half-Holiday Association. 
At approximately 23:23, the train collided with the 'Scotch express' mail train, with the brake van and the last two carriages bearing the brunt of the impact.

\section{Image}

These final two carriages experienced the worst damage, 'where the most heart-rending cries were proceeding. ${ }^{32}$ Many passengers were injured, and four of them died.

In its reporting, the Bradford Observer noted that one of the decedents 'was insured for $£ 100$ in the Railway Passengers' Assurance Company'. The introduction of medicolegal concerns here is not coincidental; the history of railway trauma in both England and in the USA is co-extensive with a dramatic rise in tort litigation, significant portions of which were connected to the railroad industry in both nations. ${ }^{33}$ Moreover, nervous injury (under which both railway spine and many forms of pain were often classified) as a sequelae of railway accidents was increasingly discussed in medicolegal terms. British surgeon Edwin Morris noted as such in 1868:

Bringing actions against railway directors for the slightest personal injury sustained in a railway accident has become of late very prevalent, and this is owing unquestionably to the prominent manner in which injuries of the nervous system, caused by railway accidents, have been thrust before the public... ${ }^{34}$

A passenger on the unfortunate Kildwick train named George Edwin Hall reported various symptoms after the accident. His knees were bruised and swollen, he 'felt very much shaken and had palpitation.... ${ }^{35}$ He remained abed for several weeks, and even after returning to work in November, he still felt 'weak, and unable to do the work I was doing before, and of much more palpitations than I used to have and am more easily excited'. ${ }^{33} \mathrm{He}$ complained of significant pain in his right side, and filed a claim for damages against the Midland Railway Company. A consulting surgeon named Thomas Scattergood examined Mr. Hall. Scattergood was renowned for his expertise both in forensic medicine and in accident compensation. He noted in his report:

I consider that Hall may have suffered to some extent from shock, and from bruises about the knees: he is nervous and excitable: the receipt of a telegram from his Solicitor today announcing that the trial was fixed for Monday put him quite into a flurry. His only actual disease is a disease of the mitral valve of the heart. This is not due to the accident, but is the result of the attack of rheumatic fever from which he suffered 8 months previously. $^{33}$

The adjective 'actual' here is crucial. What is the criteria that distinguish 'actual' from 'non-actual' or 'unreal' disease? Although railway surgeons are hardly unbiased observers, we can analyse that bias as a way of identifying what the root of their concerns. In a medicolegal context, railway surgeons repeatedly decried the plaintiff's expert witness testifying as to the existence of lesions. American railway surgeon Arthur Dean Bevan noted in 1895 that the 'absence of postmortem evidence' in cases of railway spine prompted neurologists to 'theorise learnedly on the pathology and attempt to make their theories confirm to the multiform symptoms presented'. ${ }^{36}$ Lamenting the effort to prove the existence of 'real injuries' by reference to 'actual lesions', Bevan observed that

[f]or a time at least the condition of railway spine...was accepted as a demonstrated and frequent surgical lesion. It is unnecessary for me to mention what an important fact the recognition of this condition became in a medico-legal way and how the recognition of the disease cost millions of dollars to corporations.... Then later with further study the railway surgeon became convinced that concussion of the spine... was a myth. ${ }^{34}$

Similarly, American neurologist Charles Dana remarked in 1884 that 'the more we shall get into the habit of including a thorough examination of the cord and its meninges in postmortem, the more our knowledge on the demonstrable lesions will increase, and the less we shall hear about the concussion of the spine'. 37

It is the presence of the lesion that grounds the clinical reality of railway spine. In the absence of pathology there is no actual disease. There is only the presence of what in the 20th century would come to be called litigation or traumatic neurosis, which is a neurotic condition subsequent to a traumatic incident that is fuelled by the possibility of compensation. In 1889, American surgeon Herbert Judd opined that in two decades of experience, he had found only two genuine cases of spinal concussion, both occurring in cases where there was no litigation and hence no chance of obtaining compensation. ${ }^{38}$ Writing on the subject in 1926, British dermatologist Frederick Parkes Weber observed that ' $[t]$ here is often a motive...for the patient not to allow himself to recover or be cured (question of assurancecompensation, etc)'. ${ }^{39}$ Weber further explained that

[w] hen a person has only himself to blame and has no chance of compensation, and has no object in remaining ill, he usually gets well and returns to work or his business or pursuit, whatever that may be, as soon as can be hoped for ... sometimes he has to be restrained from working too soon! ${ }^{37}$

The key is that the legitimacy of railway spine turned on the existence of lesions that could be clinically correlated with the patient's illness complaints, which often centred on chronic, non-specific symptoms such as pain and lethargy. The absence of such lesions was generally problematic for physicians and laypeople alike in the late Victorian and early Edwardian/ Progressive periods. Judd actually frames the issue in terms of the familiar objective/subjective dichotomy: 'a person can claim to be injured in a collision of trains...no objective symptoms or signs can be discovered.... Such cases can be and are based on... only a few subjective symptoms, every one of which depends alone on the word of the claimant who seeks damages'. ${ }^{36}$ Whereas the epistemic valence of mechanical objectivity depends on natural objects (in this case, the lesions) and the removal of human influence, for Judd, a vastly inferior-indeed, downright untrustworthy-method of knowledge production relies for its veracity primarily on the words uttered by humans to express their lived experiences.

There seems little question that this scepticism about a patient's experiences of pain and suffering qualifies as stigma. Tracking Miranda Fricker's influential concept of epistemic injustice, Carel and Kidd $^{40}$ have argued that a provider's denial of a patient's expression of pain is a form of testimonial injustice. Due to prejudice, the provider here has attributed a deficit of credibility to the speaker and has denied the speaker's ability to narrate their own illness experiences. Thus, denial of the illness sufferer's cry of pain is a manifestation of 'stigma power'. ${ }^{41}$ Delegitimising narratives of pain is testimonial injustice. It is stigma. ${ }^{42}$

Moreover, insofar as frameworks of somaticism and mechanical objectivity both privilege scientific sight, novel medical imaging techniques become important sites for analysis. In the period, no such technique even approaches the vast significance of the X-ray, a technology epistemically powerful enough to 
motivate some early roentgenologists to risk knowingly mutilation and death for its gaze. ${ }^{43}$ Although full exploration of the connections between early roentgenology, objectivity and pain is reserved for future work, it is worth noting here that some investigators heralded the X-ray as the key to eliminating the perceived deception surrounding railway spine. American roentgenologists Frances Carey Byrne and Henry Cassidy proclaimed in 1902 that

One can predict positively that those mysterious 'railway spines' and conditions of like nature will disappear under the searchlight that Rontgen has put into our hands. Damage suits against manufacturers, casualty and railroad companies must have a surer basis in many particulars before the legal profession will father such cases. $^{44}$

This quote is exceptional, as it integrates ideas of somaticism, truth and mechanical objectivity into a single encapsulation of key anxieties that attended railway spine.

These anxieties and their connection to lesions that could be seen or 'imaged' is in part why Sir John Erichsen's 1867 treatise On Railway and Other Injuries of the Nervous System generated such intense controversy in its time. Erichsen grounded the nervous injuries that attended railway accidents in spinal lesions, countering the widespread views that complaints of pain following a railway accident had no material correlates. Erichsen's beliefs had profound medicolegal implications, as Harrington notes: 'From the 1860s onwards, lawyers, judges and juries were increasingly taking advantage of the concept of nervous shock as an organic injury, explicitly rejecting...the view that it was a purely mental, emotional or 'moral' condition without an organic basis, in order to inflict punitive damages on railway companies...' 25

It is the framework of mechanical objectivity that explains the significance of the somaticist position: pain not seated in any apparent lesion was highly problematic and was much more likely to produce doubt insofar as the natural object of illness could not be represented in any scientific investigation. Railway spine is not the only example of such a problematic form of pain without lesion at the time; historians have noted that phantom limb pain posed similar impediments for late 19th century physicians, many of whom struggled to make sense of the phenomenon in the absence of material pathologies with which to correlate. ${ }^{23}$

Moreover, as many of the sources noted above underscore, the epistemic approach to railway spine is not limited to British contexts. For an especially pointed American example, consider an 1888 railway injury case decided by the Supreme Court of Wisconsin entitled Abbott $v$. Tolliver. ${ }^{45}$ In that case, the plaintiff sustained injuries after a train owned by the Wisconsin Central Railroad Company derailed between Dorchester and Stetsonville in April 1886. 'The parlour car in which she was riding got partially off the track, made a larch, and threw the plaintiff, as she was rising from her chair, down on the floor in the centre of the car; and while she was attempting to rise she was again thrown backwards in a sitting position'. ${ }^{43}$ In terms of injuries,

[h]er left arm and limb were numb; 'she was in sinking spells most of the time, and was in pain all over ...' She suffered from pain in her spine and womb. Dr Hosmer, who was called to attend her the night she reached home, says she complained of her womb, and he found she was sore up and down the back; he saw no black and blue spots on her body anywhere, but her spine was sensitive or tender. When he made an examination, as he did some weeks after the accident, he found a displacement and laceration of the womb, and he thought there was more or less concussion of the spinal column.

In consultation with Dr Hosmer, a second physician named Dr Madden examined the plaintiff. His perspective is crucial; he 'thought she was suffering from no organic trouble except the displacement or inflammation of the womb. He discovered no symptoms of any organic disease of the spine, except the statements of the plaintiff'. ${ }^{43}$ Akin to the medical perspective in the Kildwick Accident, here again we see the dominance of frameworks of somaticism and mechanical objectivity. There is no organic disease of the spine absent structural pathologies that can be clinically correlated; in the absence of those pathologies, the illness sufferer's pain is dubious. Such doubt is a form of testimonial injustice and stigmatises the illness sufferer.

In the trial court, the plaintiff prevailed and the jury awarded her US\$7000. As the Court indicated that the defendants' negligence was undisputed, the sole question presented was whether the damages award was excessive. The Court's analysis on this issue is remarkable. They reason that 'the medical testimony offered on her side does not satisfactorily show that she suffered any permanent injury to the spine by the fall'. The defendants' expert physicians had demonstrated to the Court's satisfaction that

if there had been any concussion of the spine, there would be some indications of paralysis resulting from it, and none such was shown. They thought all the real pain which the plaintiff suffered was caused by the disease and laceration of the womb; and all the physicians agreed that this womb difficulty was not produced by the shock or fall in the car. ${ }^{43}$

The physicians' strategy here was not to deny the reality of spinal concussion, but instead to point out that its presence is correlated with severe and highly visible symptoms such as paralysis. (It is relevant that 19th century commentators concerned with malingering devised tests for the purpose of distinguishing between feigned and real paralysis). ${ }^{23}$ Moreover, the Court's perspective on the plaintiff's pain is obviously gendered: Her pain is centred in her womb. There is, of course, a long history in which various theories of the womb have been used to delegitimise and invalidate women's pain, ${ }^{29} 46-48$ and this discourse remained viable ${ }^{\text {iv }}$ in the late 19 th century. ${ }^{23} 49$

In case, there remains any doubt of the extent to which gendered constructions of pain influenced the Court's ruling, the Court actually went on to repudiate the trial court's charge to the jury that the plaintiff's 'unchaste' status is legally irrelevant:

We do not wish to intimate that an unchaste woman who is maimed and disabled by an accident on the rail-road may not suffer as much pain of body or anxiety of mind as a virtuous woman would from a like injury; but still, when it comes to a question of awarding damages, it may be that a jury would not give-perhaps ought not to give- the same damages for injuries to an unchaste woman that they would allow a virtuous, intelligent, and industrious woman, who could command good wages or take care of a family. ${ }^{43}$

The Court earlier explicitly mentioned that the plaintiff was a 'large woman, weighing about 200 pounds'. ${ }^{43}$ Thus, the Court's

${ }^{\text {iv }}$ This is to say nothing of the racialised aspects of pain in both the UK and the USA, the latter of which closely tracked the deep influence of chattel slavery and its aftermath. As the recent work by Wailoo and Hoffman et al shows there is evidence that past attitudes regarding race and pain continue to exert an influence in stigmatising people of colour in the USA today, exploration of which is reserved for future work. 
stigmatising depiction of the plaintiff as a fat, unchaste woman with 'womb difficulty' obviously portends its ultimate decision to reverse the trial court and remand for a new trial. Because stigma is inextricably linked to social power structures, the plaintiff's membership in several marginalised groups (female, fat, 'unchaste') contributes to her stigmatisation. However, the argument is that status as a pain sufferer is similarly marginalised due to its epistemic problems. As the sources surveyed here demonstrate, pain without lesion presented specific epistemic concerns that render such complaints particularly active foci for scepticism, testimonial injustice and corresponding stigma.

Unsurprisingly, then, the Court noted that even the plaintiff's physicians either deemed her to be improving or to have 'no organic trouble of the nervous system', and concludes with the epistemic coup de grace: 'The physicians on the part of the defence were of the opinion that her pains were largely imaginary or feigned'. ${ }^{40}$ Although the Court stops short of explicitly endorsing this position, they did not need to do so; they simply reasoned that the evidence supporting the idea of a permanent spinal injury was unsatisfactory, and hence that the damages award was excessive.

Although Abbott v. Tolliver is remarkable in that it shows a sitting US state supreme court's explicit reliance on highly gendered and somaticist constructions of pain to stigmatise a pain sufferer, such a disposition is hardly isolated within American jurisprudence on railway injury. ${ }^{50-52}$ The ultimate point is the extent to which changing epistemic frameworks of objectivity and somaticism meld with the various social anxieties of the late Victorian era to create doubt and scepticism as to pain without lesion. I do not claim here that such scepticism as to pain is universal-obviously not all physicians doubted their patients' pain -but merely that such scepticism increases in the 19th-20th century at least in part because of the influence of changing ideas of truth and objectivity during this time.

What does this connection have to do with contemporary difficulties in shaming and stigmatising pain sufferers?

\section{PAIN AND DOUBT, PAST AND PRESENT}

The temporal aspect of pain is important. The speaker in Dickinson's classic poem points out that 'It cannot recollect/ When it began, or if there were/A day when it was not'. ${ }^{53}$ The pain personified has no memory of its beginning; it has always been there. This almost timeless, eternal quality of pain is consistent with what pain sufferers report as their lived experience. Accordingly, present analysis of pain may bear more (and certainly no less) connection with its past than other forms of illness experiences over time. This is not an ahistorical claim that pain is perfectly consistent across time and space, but is rather an assertion, founded on the kinds of evidence touched on here, linking epistemic frameworks that begin to wax in the late 19th century to contemporary attitudes, practices and beliefs towards pain sufferers today.

The rise of somaticism and mechanical objectivity as to medicine and therapeutics unquestionably contributed to what Jewson famously termed 'the disappearance of the sick man' in the modern era. ${ }^{54}$ It was the pathological processes underlying illness sufferer's symptoms that contained truth. Hence, wretched Ivan Ilyich discovered that the modern doctor was disinterested in Ilyich's existential question ('is the illness serious'): 'It was not a matter of Ivan Ilyich's life but a conflict between a floating kidney and a disease of the caecum. And in Ivan Ilyich's presence the doctor resolved that conflict brilliantly in favour of the caecum.... 55 In contrast to Ilyich's mortal illness, pain without lesion defies knowledge-making processes that rely on natural objects (pathologies) that can be clinically correlated with the patient's illness complaints. While somaticism and mechanical objectivity are 19th century frameworks in origin, as ethnographies of pain demonstrate, they remain viable and active conceptual schemes through which pain and illness are negotiated in the West today.

For example, in the study by Rhodes et al on chronic low back pain, the authors found that the visualisation of the inner body afforded by medical imaging grounded the validity of the pain sufferers' experiences. Informants reported relief when the imaging studies revealed signs of pathology, 'proof' that they were not just 'going crazy or complaining, ${ }^{56}$ Moreover, '[a]s the link between pain, diagnosis and possible relief, test results can become the final authority, something that must be insisted on, regardless of cost or resistance from the physician, because only the test can show what is "really" there'. ${ }^{52}$ By visually representing the pathologies inside the human body, the truth of the phenomenon in question can be discerned. But note that it is not merely the physician qua investigator who uses images of the anatomised body to verify the truth of the matter. The pain sufferer himself/herself/themselves also draw on the epistemic power of the correlative pathological object inside the human body. While pain sufferers do not have the luxury of denying the reality of their pain, they can and do deny its legitimacy, thereby internalising the stigma so frequently directed at people in pain.

\section{CONCLUSION}

History is a circle, not a line. The worlds we live in are created anew everyday by the warp and weft of that history. The modern history of pain without lesion has an enormous impact in shaping attitudes, practices and beliefs towards pain and those who experience it. It is naïve to think that we can resolve the deficiencies in our behaviour towards people in pain without attending to the deep historical roots of those deficiencies. Of course, how people living today can own problematic histories, engage them and wield them to build a better world are difficult questions. But whatever steps are needed to accomplish these tasks are impossible without a basic recognition of the extent to which the histories do in fact shape the present. As to pain, this is a point which clinical leaders in pain management have already acknowledged. ${ }^{10}$

\section{Twitter Follow Daniel Goldberg @prof_goldberg}

Acknowledgments The author would like to acknowledge the advice and encouragement of Joanna Bourke, Louise Hide, and Carmen Mangion during the course of The Birkbeck Pain Project (now The Birkbeck Trauma Project). Thanks are also owed to panelists lan Burney and Christopher Hamlin for inviting me to present an early draft of this paper at the 2014 annual meeting of the American Association for History of Medicine, and to the audience for questions and feedback.

Funding The historical research undertaken in this manuscript was supported by an honorary fellowship with The Birkbeck Pain Project, funded by The Wellcome Trust.

Competing interests None declared.

Provenance and peer review Not commissioned; externally peer reviewed.

\section{REFERENCES}

1 Perez-Brumer A, Hatzenbuehler ML, Oldenburg $C E$, et al. Individual- and structural-level risk factors for suicide attempts among transgender adults. Behav Med 2015;41:164-71.

2 Hatzenbuehler ML, Phelan JC, Link BG. Stigma as a fundamental cause of population health inequalities. Am J Public Health 2013;103:813-21.

3 Jackson JE. Stigma, liminality, and chronic pain: mind-body borderlands. American Ethnologist 2005;32:332-53. 
4 Jackson JE. "Camp pain": talking with chronic pain patients. Philadelphia PA: University of Pennsylvania Press, 1999.

5 Upshur CC, Bacigalupe G, Luckmann R. "They don't want anything to do with you": patient views of primary care management of chronic pain. Pain Med 2010;11:1791-8.

6 Link BG, Phelan JC. Stigma and its public health implications. Lancet 2006:367:528-9.

7 Goldberg DS. Intervening at the right point in the causal pathway: law, policy, and the devastating impact of pain across the globe. Annals of Health Law 2013:22:198-223.

8 Cohen E. The modulated scream: pain in late medieval culture. Chicago, IL: University of Chicago Press, 2010.

9 Biro D. The language of pain: finding words, compassion, and relief. New York: WW Norton \& Company, 2010.

10 Leder D. Illness and exile: Sophocles' Philoctetes. Lit Med 1990;9:1-11.

11 Hodgkiss A. From lesion to metaphor: chronic pain in British, French, and German medical writings, 1800-1914. Amsterdam: Rodopi Bv Editions, 2000.

12 Hill CS Jr. When will adequate pain treatment be the norm? JAMA 1995;274:1881-2.

13 Daston LJ, Galison P. Objectivity. New York, NY: Zone Books, 2007

14 Goldberg DS. The transformative power of X-rays in U.S. Scientific \& Medical Litigation: mechanical objectivity in Smith v. Grant (1896). Persp Sci 2013;21:23-57.

15 Foucault M. The birth of the clinic: an archaeology of medical perception. trans. A. M.S. Sheridan. New York, NY: Vintage Press, 1994.

16 Duffin J. To see with a better eye: a life of RTH Laennec. Princeton NJ: Princeton University Press, 1998.

17 Hammond WA. Spinal Irritation (Posterior Spinal Anemia). Detroit, MI: George S Davis, 1886:35.

18 Ray R. The History of Pain. Cambridge, MA: Harvard University Press, 1998:99.

19 Goldberg DS. Pain without lesion: debate among American neurologists, 1850-1900. 19: Interdisciplinary Studies in the Long Nineteenth Century 2012;15. doi:http://doi.org/10.16995/ntn.629.

20 Rosenberg CE. Contested boundaries: psychiatry, disease, and diagnosis. Perspect Biol Med 2006;49:407-24.

21 Sheehan T. Doctored: the medicine of photography in nineteenth-century America. University Park, PA: Pennsylvania State University Press, 2011.

22 Rogers M. Delia's tears: race, science \& photography in nineteenth-century America. New Haven, CT: Yale University Press, 2010.

23 Holmes MS. Fictions of affliction: physical disability in Victorian culture. Ann Arbor Ml: University of Michigan Press, 2009.

24 Goldberg DS. "What they think of the causes of so much suffering": S Weir Mitchell, John Kearsley Mitchell, and ideas about phantom limb pain in late 19th c. Spontaneous Generations 2016:8:27-54.

25 Caplan EM. Trains, brains, and sprains: railway spine and the origins of psychoneuroses. Bull Hist Med 1995;69:387-419.

26 Harrington R. On the tracks of trauma: railway spine reconsidered. Soc Hist Med 2003:16:209-23.

27 Keller T. Railway spine revisited: traumatic neurosis or neurasthenia? J Hist Med Allied Sci 1995:50:507-24.

28 Caplan EM. Trains and trauma in the American gilded age. In: Micale MS, Lerner $\mathrm{P}_{1}$ eds. Traumatic pasts: history, psychiatry, and trauma in the modern age, 1870-1930. Cambridge UK: Cambridge University Press, 2010:57-80.
29 Harrington R. The railway accident: trains, trauma, and technological crises in nineteenth-century Britain. In: Micale MS, Lerner P, eds. Traumatic pasts: history, psychiatry, and trauma in the modern age, 1870-1930. Cambridge, UK: Cambridge University Press, 2010:31-56.

30 Bourke J. The story of pain: from prayer to painkillers. New York: Oxford University Press, 2014.

31 Not a case of railway spine. JAMA 1895;24:446.

32 Railway collision at Kildwick. The Bradford Observer, 30 Aug 1875.

33 DeVille K. Medical malpractice in nineteenth-century America: origins and legacy. New York: New York University Press, 1992.

34 Morris E. A practical treatise on shock after surgical operations and injuries: railway accidents. Philadelphia, PA: J.B. Lippincott \& Co., 1868:48.

35 Scattergood T. Reports on Three Railway Accident Cases. The Wellcome Library, Thomas Scattergood Collection, MS 4412, Part 28.

36 Bevan AD. Real and alleged injuries of the spine. Railway Surg 1895:2:121-30.

37 Dana CL. Concussion of the spine and its relation to neurasthenia and hysteria. The Medical Record 1884;26:617-21.

38 Judd $\mathrm{H}$. The medico-legal aspect of concussion of the spine. JAMA 1889:13:188-94.

39 Traumatic Neuroses or Traumatic Neurasthenia; and the Nervous Element in Accident Claims. The Wellcome Library, Frederick Parks-Weber Collection PP/FPW/ B.360/2

40 Carel H, Kidd IJ. Epistemic injustice in healthcare: a philosophical analysis. Med Health Care Philos 2014;17:529-40.

41 Link BG, Phelan JC. Stigma power. Soc Sci Med 2014;103:24-32.

42 Buchman DZ, Ho A, Goldberg DS. Investigating trust, expertise, and epistemic injustice in chronic pain. J Bioeth Inq. Published Online First: 22 Dec 2016 doi:10.1007/s11673-016-9761-x.

43 Goldberg DS. Suffering and death among early American roentgenologists: the power of remotely anatomizing the living body in fin de siècle America. Bull Hist Med 2011:85:1-28.

44 Byrne $\mathrm{FC}$, Cassidy H. A resume of X-ray work, with some personal observations. $M d$ Med J 1902:45:519.

4536 N.W. 622 (Wisc. 1888)

46 Morris D. The culture of pain. Berkeley, CA: University of California Press, 1991

47 Moscoso J. Pain: a cultural history. Basingstoke: Palgrave MacMillan, 2012.

48 Wailoo K. Pain: a political history. Baltimore: Johns Hopkins University Press, 2014.

49 Hoffman KM, Trawalter S, Axt JR, et al. Racial bias in pain assessment and treatment recommendations, and false beliefs about biological differences between blacks and whites. Proc Natl Acad Sci USA 2016;113:4296-301.

50 Thompson v. Manhattan Ry Co., 11 A.D. 182 (N.Y. 1896)

51 Maynard v. Oregon RR Co., 72 P. 590 (Oregon 1903)

52 Pittsburgh \& St. L. Ry. Co. v. Story, 63 III. App. 239 (III. App. Ct. 1896)

53 Dickinson E. Pain has an element of blank. In: Franklin RW, eds. The poems of Emily Dickinson. Cambridge, MA: Harvard University Press, 1998.

54 Jewson ND. The disappearance of the sick man from medical cosmology, 17701870. Sociology 1976;10:225-44.

55 Leo Tolstoy. The death of Ivan Ilyich. Trans. Lynn Solotaroff. Bantam Books, 2004:65 Rhodes LA, McPhillips-Tangum CA, Markham C, et al. The power of the visible: the meaning of diagnostic tests in chronic back pain. Soc Sci Med 1999;48:1189-230. 